Etnográfica

Revista do Centro em Rede de Investigação em

Antropologia

vol. $18(2) \mid 2014$

Vol. $18(2)$

\title{
Entre o idealizado e o exequível: memórias da primeira mulher antropóloga portuguesa
}

Entrevista com Maria Beatriz Rocha-Trindade

Marina Pignatelli e Maria Beatriz Rocha-Trindade

\section{(2) OpenEdition}

Journals

Edição electrónica

URL: https://journals.openedition.org/etnografica/3783

DOI: 10.4000/etnografica.3783

ISSN: 2182-2891

Editora

Centro em Rede de Investigação em Antropologia

Edição impressa

Data de publição: 1 junho 2014

Paginação: 443-455

ISSN: 0873-6561

Refêrencia eletrónica

Marina Pignatelli e Maria Beatriz Rocha-Trindade, «Entre o idealizado e o exequível: memórias da primeira mulher antropóloga portuguesa», Etnográfica [Online], vol. 18 (2) | 2014, posto online no dia 22 julho 2014, consultado o 11 fevereiro 2022. URL: http://journals.openedition.org/etnografica/3783 ; DOI: https://doi.org/10.4000/etnografica.3783

\section{(c) (i) (9)}

Etnográfica is licensed under a Creative Commons Attribution-NonCommercial 4.0 International License. 


\title{
Entre o idealizado e o exequível: memórias da primeira mulher antropóloga portuguesa
}

\section{Entrevista com Maria Beatriz Rocha-Trindade}

\author{
Por Marina Pignatelli
}

Maria Beatriz Rocha-Trindade, nascida em Faro, socióloga, é doutorada pela Universidade de Paris V (Sorbonne) e agregada pela Universidade Nova de Lisboa (FCSH). É professora catedrática na Universidade Aberta, onde fundou (em 1994) o Centro de Estudos das Migrações e das Relações Interculturais/CEMRI, Unidade de I\&D da Fundação para a Ciência e a Tecnologia, do Ministério da Educação e Ciência. É consultora científica do Museu da Emigração e das Comunidades de Fafe. Introduziu em Portugal o ensino da sociologia das migrações (na Universidade Católica, no curso de Teologia, em 1994; a partir de 1996, na Universidade Aberta, a nível de licenciatura e de mestrado). É autora de uma vasta bibliografia sobre matérias relacionadas com as migrações e é colaboradora habitual e referee de revistas científicas internacionais neste domínio. É membro de diversas organizações científicas portuguesas e estrangeiras, designadamente da Comissão Científica da Cátedra UNESCO sobre Migrações, da Universidade de Santiago de Compostela, na Galiza. Recebeu a Medalha de Mérito do Município de Fafe e foi distinguida pelo Comité National Français en Hommage à Aristides de Sousa Mendes (Hendaye, 2012), pelo seu pioneirismo na investigação da emigração, e também pela Obra Católica Portuguesa das Migrações (OCPM, Lisboa, 2012) pela vida de trabalho académico sobre migrações, pelo empenho na causa dos migrantes e pela colaboração voluntária e generosa com a OCPM. É titular da Ordre National du Mérite, de França, com o grau de Chevalier, e da Grã-Cruz da Ordem da Instrução Pública, de Portugal.

PIGNATELLI, Marina (mpignatelli@iscsp.ulisboa.pt) - Centro em Rede de Investigação em Antropologia; Instituto Superior de Ciências Sociais e Políticas, Universidade de Lisboa, Portugal. 


\section{MARINA PIGNATELLI Como aconteceu a escolha do curso de antropologia?}

MARIA BEATRIZ ROCHA-TRINDADE A frequência do curso de Ciências Antropológicas e Etnológicas, então ministrado pelo Instituto Superior de Ciências Sociais e Política Ultramarina (ISCSPU), mais do que uma escolha, decorre da imposição que me foi feita pelo próprio instituto ao estabelecer o convite para nele lecionar como assistente.

Tinha regressado de França, onde me tinha sido proporcionado realizar um estágio de alguns meses no Centre d'Etudes Sociologiques e, por proposta do seu diretor, professor Jean Stoetzel, foi-me sugerido submeter a candidatura ao doutoramento em Sociologia. ${ }^{1}$ Depois da aprovação num exigente exame que avaliou, por um lado, o nível científico dos meus conhecimentos na área, por outro, o domínio escrito e falado da língua francesa, fui autorizada a inscrever-me e a frequentar os seminários de investigação conducentes à obtenção desse grau académico. A tese, orientada pelo professor Alain Girard, foi apresentada à Universidade René Descartes (Paris V - Sorbonne) e nela defendida em provas públicas no ano de 1970.

Ao ser abordada nesse mesmo ano pelo ISCSPU, abria-se-me a porta dourada do instituto que tinha frequentado como aluna (já com família constituída) e os ensinamentos então colhidos no curso de Administração Ultramarina (no qual tive um lugar pioneiro por ter sido, em 1962, a primeira mulher nele inscrita) possibilitaram que a visão alargada sobre o grande espaço transcontinental que constituía o país de então fosse muito atrativa e me abrisse novas perspetivas. Por ser muito diversificado e muito interessante todo o acervo de conhecimentos que conseguira reunir, creio ter sido ele o verdadeiro responsável por ter querido aprender mais sobre tudo o que sendo "nosso" se situava fora do espaço continental português.

Aceitar a proposta que me fora dirigida criou em mim grandes expectativas, por julgar ser possível vir a encontrar, no percurso que assim se me abria, todas as possibilidades de realização face ao plano anteriormente traçado para a minha própria vida profissional. Poderia dessa forma reencontrar a instituição universitária de que guardava e continuo a guardar a melhor recordação e nela vir a aceder ao estatuto de docente, o que largamente iria compensar todos os esforços até aí despendidos.

I Jean Stoezel e Alan Girard, ambos professores na Sorbonne, partilhavam a direção do Departamento de Psicologia Social no Institut National d'Etudes Démographiques (INED). No meio do século passado publicam o livro Français et immigrés, vol. I: L'attitude française, l'adaptation des Italiens et des Polonais (Presses Universitaires de France/Institut National d'Etudes Démographiques, 1953), seguido de um outro que lhe dá continuidade e que tem como subtítulo Nouveaux documents sur l'adaptationAlgériens, Italiens, Polonais, le service social d'aide aux immigrants (Presses Universitaires de France/Institut National d'Etudes Démographiques, 1954). Constituem um marco no panorama da literatura científica relacionada com o fenómeno migratório e são hoje considerados uma referência. 
Devo abrir um parêntesis para reconhecer que um certo idealismo se aliava a uma total inexperiência, o que, de certo modo, explica todo o entusiasmo sentido... Fiquei, no entanto, um pouco chocada com o caminho que o Instituto me impunha sem alternativa, por me colocar numa posição delicada, ao mesmo tempo incómoda e difícil, ao exigir um esforço suplementar que obrigaria a acumular duas funções dentro da mesma instituição: a de aluna e a de assistente.

Realizar a preparação das aulas num primeiro ano de docência constituiu uma tarefa de grande exigência e a lecionação da disciplina de Metodologia de Investigação em Ciências Sociais, que me veio a ser conferida, obrigava a um intenso trabalho, do qual ressalto o estudo de uma vasta bibliografia. O curso que frequentei em paralelo obrigava também a conhecer matérias de outra natureza, que exigiam disponibilidade e muitas horas de estudo diárias para poder consultar tudo o que deveria ser lido. Neste âmbito, a influência dos autores americanos sempre prevaleceu na orientação prestada e a excelência dos seus trabalhos foi também sempre apresentada em claro detrimento da produção científica francesa, o que, devo dizer, me causava um certo choque. Ser ao mesmo tempo docente e discente sob a cúpula da mesma instituição universitária, no exercício de funções diferenciadas e com estatuto diferente, não foi uma tarefa fácil, pois cada um dos lados em que nos encontramos projeta a nossa imagem sobre o outro. Havia que saber mantê-la em simultâneo. Alegro-me por tal ter acontecido. Terminei a licenciatura com média de 17,4 e continuo a manter uma relação cordial e amiga com alguns dos meus antigos estudantes. Sem ser possível enumerar o nome de todos eles, cito, meramente a título de exemplo, alguns dos que mais se destacaram: o embaixador Seixas da Costa, Maria do Rosário Carneiro, que tem desenvolvido funções na carreira política e universitária, António Sousa Lara, também ex-deputado e igualmente com funções universitárias, tal como Hermano Carmo e Fausto Amaro (três professores catedráticos do ISCSP).

MP Era a única mulher a frequentá-lo? Outras não havia ou desistiram? Como era o "espírito da época" sobre o curso e sobre mulheres a frequentá-lo?

MBR-T O curso de Ciências Antropológicas e Etnológicas tinha uma frequência mista mas muito restrita em número, e ao longo dos dois anos de lecionação/aprendizagem, que no início do primeiro integravam o quadro teórico que o sustentava, foram progressivamente desistindo alguns dos estudantes inscritos. Lembro com saudades professores e alunos de um grupo que incluía um conjunto muito diversificado de pessoas. Entre eles, três psiquiatras, Margarida Cordeiro, Nuno Afonso Ribeiro e mulher; Olímpio Nunes, professor na Casa Pia, que veio a publicar uma das primeiras obras escritas sobre os ciganos portugueses (O Povo Cigano, 1981); Diogo Moreira, então funcionário 
da Lever que, posteriormente como professor catedrático e investigador no ISCSP, veio a realizar uma brilhante carreira universitária; ainda o Cardoso, cabo-verdiano de origem, muito mais jovem, que veio a ocupar um importante lugar no governo do seu país, entre alguns outros que guardo na memória, mas cujos nomes se me varreram.

Para a grande maioria dos que o frequentavam constituía motivação primeira poder seguir o ensino formal de matérias que entendiam servir de incondicional apoio para o exercício da profissão que desempenhavam. No entanto, realizar "trabalho de campo" fora da sua área de inserção - que poderia constituir uma das mais interessantes facetas de aplicação dos ensinamentos colhidos -, por não se encaixar nas perspetivas de curto prazo, as responsabilidades já assumidas não o permitiam. Razões de natureza pessoal provocaram, certamente, o abandono por alguns deles que a vida profissional dispersou e nem sequer vieram a completar o curso. Com o correr do tempo, "obrigações e devoções" fizeram diluir o relacionamento existente entre todos os que o completaram e a relação tão próxima que existia desfez-se por completo. O primeiro abandono deve-se a Margarida Cordeiro - fê-lo por querer colaborar com o seu marido, cineasta António Reis, com quem realizou o filme Trás-os-Montes (1976).

Os alunos que o frequentaram fizeram-no em pé de igualdade e, da mesma forma, foram sempre tratados sem qualquer atitude discriminatória.

Foi minha convicção que a imagem da investigadora Margot Dias (mulher e membro da equipa liderada por Jorge Dias) diluía qualquer preconceito, se para tal tivesse havido lugar, em relação à restrição que eventualmente poderia ter sido levantada em relação às mulheres antropólogas. Para além disso, o renome alcançado por Ruth Benedict (1887-1948) e Margaret Mead (1901-1978), académicas de valor incontroverso que fizeram a sua formação e ensinaram na Universidade de Columbia, em Nova Iorque, contrariava por completo qualquer hipótese de discriminação.

MP O que recorda do curso? Que efeitos teve essa formação e experiência, durante o curso e depois, tornando-se a primeira graduada em antropologia do país?

MBR-T Não é de mais repetir quanto gostei de ter frequentado este curso e, entre a diversidade de competências que possuíam e também as diferentes qualidades pedagógicas que caracterizavam os seus docentes, recordo grandes professores que nele se distinguiram. Consideraria incorreto citar os seus nomes, tal como emitir publicamente juízos de valor a seu respeito. Em espaço de aula que, pela participação ativa do reduzido número de estudantes, se transformava em seminário de investigação, constituíram-se unidades letivas em que o confronto de ideias se fazia de forma aberta, servindo de estímulo ao aprofundamento das temáticas inscritas em cada uma delas. Uma competição 
saudável instalava-se entre colegas que aproveitavam todas as oportunidades que surgiam para ler novos autores e adquirir novas obras que nem sequer tinham sido indicadas pelos próprios professores.

A leitura dos muitos livros que constituíam a bibliografia de referência, cuja consulta era obrigatória, bem como os ensinamentos transmitidos provocaram em todos nós um crescente entusiasmo que ainda recordo. Um mundo novo ia-se abrindo e fazia também construir novos projetos. O mercado livreiro de então, nada tendo a ver com o de hoje, levava a que a aquisição de publicações só pudesse, em muitos casos, ser resolvida pela saída de alguém do país. Era uma forma de resolver a situação que se colocava, pois tornava-se impossível concretizá-la por intermédio de livrarias, revelando-se quase sempre um processo muito moroso.

No âmbito do ISCSPU, a figura do professor doutor Jorge Dias foi sempre apresentada com o respeito e a admiração que lhe eram devidos e quase que uma devoção pairava em torno dele. Muitos dos seus ensinamentos, transmitidos por grande número de professores que frequentemente faziam referência a esta personalidade, lembravam o papel que desempenhou na instituição da disciplina em Portugal, o papel que ocupava no quadro universitário nacional e internacional e, de forma mais incisiva, no Instituto Superior de Ciências Sociais e Política Ultramarina. Destaco a seriedade com que produziu a pesquisa que realizou, cujos resultados constituíam uma referência permanente tanto na perspetiva teórica como na aplicada e foram em grande parte publicados pela própria Junta de Investigações do Ultramar (criada em 1963), da qual também era investigador.

Como assistente do ISCSPU e também na qualidade de estudante do curso de Ciências Antropológicas e Etnológicas, não só mantivera um permanente contacto com o professor Jorge Dias e com todos os investigadores que com ele trabalhavam, como segui eu própria o curso de Iniciação à Museologia, lecionado no espaço do Museu de Etnologia pelo Dr. Ernesto Veiga de Oliveira.

Tratou-se de uma influência que marcou toda a minha vida profissional. Devo-lhe o ter prosseguido uma formação nessa mesma área, à qual ainda hoje me mantenho ligada. Dela decorrem os artigos que escrevi ${ }^{2}$ e os laços que mais tarde vim a estabelecer com o Museu da Emigração e das Comunidades de Fafe, a que me encontro ligada desde a sua criação (2001). Congratulo-me pela distinção que me foi publicamente atribuída em 2008 pela presidência do

2 "Musealizar as migrações", em História (2002); "Migrations museums: permanent and temporary exhibitions", em AEMI Journal (2010); e, com Miguel Monteiro: "Les musées dédiés aux migrations: le Musée Portugais de l'Emigration”, em Museum International: Le patrimoine culturel des migrants (2007); "Emigração e retorno: imagens cruzadas num Webmuseu e o papel da tecnociência no caso de www. museu-emigrantes.org”, em A Emigração Portuguesa para o Brasil (org. Fernando de Sousa e Isménia Martins, CEPESE/Edições Afrontamento, 2007); "I musei delle migrazioni in Europa: il Museu da Emigração e das Comunidades, Fafe, Portogallo”, em Studi Emigrazione (2007). 
município, a Medalha de Mérito Concelhio, em razão de toda a colaboração prestada.

O que na realidade me apraz citar foi a iniciativa que tomei ao propor ao Conselho Científico da Universidade Aberta a criação da disciplina que veio a ser designada Iniciação à Museologia. A organização da mesma foi de imediato confiada ao Dr. Ernesto Veiga de Oliveira, que deu a todos o gosto de aceitar tal tarefa. A sua organização contaria com a colaboração de Benjamim Pereira e de um conjunto de nomes prestigiados na área. Tal não veio, lamentavelmente a ter lugar. A inesperada partida do Dr. Ernesto (1990) deixou a todos uma grande tristeza e o curso, que com entusiasmo iria organizar, ficou sem efeito. A imediata hipótese que surgiu para assegurar a sua continuidade foi confiar a organização a Benjamim. Por este não ter sido capaz de superar a perda sofrida e ter recusado assumir quer a responsabilidade quer a participação ativa na sua coordenação, depois de muita insistência e de uma longa espera para obter resposta, fui obrigada eu própria a aceitar essa "missão".

Superada a incerteza de o conseguir realizar, meti mãos à obra após ter conseguido juntar a maior parte dos colaboradores, já selecionados por Veiga de Oliveira: Fernando Bragança Gil, António Nabais, Cruz de Carvalho, Sommer Ribeiro, Elias Casanovas, Luís Raposo, Galopim de Carvalho, Baptista Pereira e Paulo Oliveira Ramos. Integravam esta unidade letiva um manual com 275 páginas, um conjunto de 12 vídeos e um Caderno de Apoio, da autoria de Isabel Moreira. A sua lecionação teve início em 1993. Ao conjunto multimédia dedicado "A Ernesto Veiga de Oliveira, 1910-1990" (vd. p. 5 do manual) foi atribuído publicamente, em 1996, pela Associação Portuguesa de Organizações Museológicas (APOM), na Figueira da Foz, o seu prémio anual. Ao recebê-lo, evoquei com emoção e lágrimas o tão querido e saudoso Ernesto.

A minha vida profissional fez-se ao longo de um percurso em que obtive ensinamentos diversificados, dentro e fora do país. Pode dizer-se que o curso, em si próprio, não teve uma ligação visível com as funções que vim a desempenhar. Constituiu certamente uma formação não negligenciável, podendo dizer-se ter sido mais um contributo que se juntou ao acervo de conhecimentos já adquiridos e me deu competências que abriram caminho às atividades que se seguiram.

MP A fundação do CEAC celebrou-se após 50 anos. A partir da sua experiência, poderá dizer-me como estava organizado, como para ele entrou e que tarefas lhe foram atribuídas?

MBR-T Depois de ter regressado a Portugal mantive um permanente contacto com o Centro de Estudos de Antropologia Cultural, que então se situava num dos andares do Palácio Vale Flor, na Rua Jau, n. ${ }^{0} 54$ (Alto de Santo Amaro, em Lisboa), onde se encontra instalado desde 1992 o Hotel Pestana Palace. 
Situado numa zona residencial da cidade de Lisboa, o edifício e os jardins que o envolvem, construídos nos finais do século XIX, estão classificados como monumento nacional. O seu acesso tinha de ser feito por um grandioso portão de ferro negro, que se mantinha sempre fechado e só era aberto por um porteiro, homem muito alto e encorpado, fardado de um verde intenso que contrastava com o galão dourado no boné e nos chumaços. $\mathrm{O}$ cumprimento que sempre me dirigia fazia-me estremecer pela formalidade que assumia a frase: "Bom dia a V. Ex. ", Senhora Doutora". Por ser uma atenção que considerava excessiva e desadequada à minha idade e à posição que então ocupava, levei expressamente alguns amigos até ao palácio, de forma a poderem presenciar a admiração que o ritual me causava.

O estado do edifício, agora restaurado, inspirava nessa altura sérios cuidados e não era muito segura a instalação dos que dentro dele trabalhavam. Vem a este propósito a recordação de toda uma tarde passada no seu elevador, que deixara de funcionar.

A atração que sempre me tinha produzido a equipa e todo o trabalho por ela desenvolvido e publicado levaram-me a decidir passar a integrá-la, por isso tendo deixado as funções desempenhadas durante três anos no ISCSPU.

O trabalho que nele viria a desenvolver seria compensado por uma pequena ajuda monetária (4000 escudos mensais, equivalentes a cerca de 20 euros - os tempos eram outros!), sem qualquer garantia ou benefício - uma retribuição semelhante à de um subsídio de investigação ou de uma bolsa de estudo sem nenhuma outra regalia suplementar.

Para ter deixado um lugar que desempenhava por contrato e onde auferia cerca de 12.000 escudos (aproximadamente 60 euros), pois à lecionação juntava a regência das disciplinas pelas quais passara a ser responsável, era necessário estar certa de que mudar valeria a pena, tendo em conta todo o prazer intelectual de pertencer ao que então entendia ser uma das melhores equipas do país (para mim, sem dúvida, a melhor!).

O professor Jorge Dias deixou-nos em fevereiro de 1973 e a minha entrada, negociada posteriormente, após proposta que o Dr. Ernesto Veiga de Oliveira me dirigira, teve a minha aceitação imediata.

Conceptualmente, a direção do Centro iria repartir pelos investigadores que o integravam temáticas de interesse correspondentes a áreas geográficas onde se desejava que um trabalho de pesquisa - análise bibliográfica e trabalho de campo - viesse a ser realizado. A mim foi-me atribuída a responsabilidade pela "América", mas nunca cheguei a trabalhar sobre ela. Isto revela um certo desfasamento entre o idealizado e o exequível...

No entanto, a complementaridade de tarefas que se interligavam no âmbito dos dois centros de investigação e do museu conduziram à atribuição de uma linha de pesquisa sobre o pastoreio, tema considerado um espaço em aberto nos estudos até então desenvolvidos. Ao prossegui-la realizei trabalho de campo no 
Algarve (Serra de Monchique e Serra de Loulé) e na Beira (Serra de Montemuro e Serra da Estrela). No interior do país, no distrito de Viseu, segui mesmo a transumância dos rebanhos desde Cavernães, passando por Mões, até chegar à vila de Castro Daire, onde uma das pernoitas se realizava. Ainda guardo na memória a visualização da chegada dos rebanhos e dos pastores; imagens que pelo deslumbre causado ficaram gravadas para sempre. Ligam-se entre si e traduzem muitos trechos do percurso: o caminhar por longos e difíceis trilhos, a ordenha e o cavar de covas onde era armazenado o leite que alimentava os cães, a sofreguidão com que era bebido, a figura dos pastores e os utensílios por eles transportados, que os acompanhavam ao longo de toda a vida nómada. A organização da viagem transumante tem por base um trabalho coletivo e exige uma complexa organização logística - a preparação deste surreal desfile e a encenação do teatro de operações nos espaços que mediavam a caminhada mereciam ser apresentados numa grande exposição que nunca veio a acontecer. A par desta linha, mantinha-se a investigação na área das migrações. Queiriga, situada no concelho de Vila Nova de Paiva (Viseu), que descobrira em França onde estava implantado o equivalente a metade da comunidade antes nela residente, constituía um permanente interesse e a essa aldeia me desloquei frequentemente. $\mathrm{O}$ trabalho de campo que desenvolvi, com estadia de alguns meses na região, permitiu recolher dados sobre os dois temas em simultâneo. Ficar alojada nessa aldeia e ter transporte próprio - um clássico "carocha" que me levou por serras e vales nas "Terras do Demo" - facilitou muito as minhas deambulações e estadia no terreno. O espaço geográfico que constituía a sede da minha residência facilitava a deslocação local. Pude assim aceder a lugares distantes onde o interesse me fazia chegar - lembro Albergaria das Cabras e Vilharigues - e centrar-me também no espaço urbano de Viseu, que possibilitou realizar pesquisa de arquivo na Casa Amarela e no Governo Civil, dando também oportunidade para "observar" celebrações tradicionais. De entre elas recordo o justificado êxtase perante as "Cavalhadas", desfile originário de Vildemoinhos, que desde o século XVII percorre anualmente as ruas da cidade no dia de São João. Ficaram as recordações e as imagens então colhidas foram guardadas.

A projeção e reconhecimento que distinguiram Jorge Dias de muitos outros professores do próprio Instituto conferiam-lhe um estatuto próprio. Soube criar uma equipa que integrava a sua própria mulher (Margot Dias) e um conjunto de colaboradores amigos: Ernesto Veiga de Oliveira, Benjamim Pereira e Fernando Galhano, que com ele vieram do Norte do país; António Carreira e Rogado Quintino, que para além da experiência profissional de terreno obtida no Ultramar (Guiné-Bissau e Cabo Verde) como administradores de posto, possuíam uma formação académica que os distinguira.

Todos eles faziam parte de uma estratégia fundamental para a qualidade que se refletiu em toda a produção científica que emanou dos centros que vieram a integrar. Os companheiros que ao longo da vida o acompanharam nunca 
traíram o seu pensamento nem a sua pessoa. Formavam uma equipa que, pela complementaridade da formação distinta de cada um deles, fez confluir as competências diversificadas que possuíam. Com um mesmo propósito, deram recorte e visibilidade à equipa do Centro de Estudos de Antropologia Cultural, a que se veio juntar, em data posterior, o já existente Centro de Estudos de Etnologia (CEE, que sucedeu ao Centro de Estudos de Etnologia Peninsular, fundado em 1947) e o Museu de Etnologia, que veio a ser criado mais tarde (1965). Não fazem parte desta informação todas as transformações que qualquer deles sofreu no título que os designava, fruto de alterações na conceção da disciplina e do itinerário que o país percorreu.

Mas a certeza de que a equipa sabia muito bem o que queria e por que sempre lutou (embora de forma diplomática e por via de algum isolamento, muitas vezes posto em causa) permitiu sobrepor a sua justa convicção, continuadamente demonstrada ao querer desenvolver de forma muito séria um trabalho científico. Conseguiram, dessa forma, ultrapassar todos os percalços que sempre ocorrem nos relacionamentos em espaço académico, dando lugar a que a sua recordação tenha conseguido manter-se viva até hoje.

O edifício onde o Museu de Etnologia atualmente se encontra, inaugurado em 1976, permitiu dar expressão ao programa definido por Jorge Dias e equipa. Uma das vertentes do trabalho deste grupo foi o recurso à imagem em todo o tipo de suporte (fotografia, filme e vídeo), atitude pioneira que levou à constituição de um fundo documental da maior importância para o conhecimento do país.

O acompanhamento da recolha de artefactos, a aprendizagem das técnicas de registo e classificação, o seu armazenamento em depósito, a organização de exposições e dos respetivos catálogos, a definição de critérios e de metodologias na orientação da pesquisa para a concretização de projetos integraram uma aprendizagem que me foi útil no desempenho de funções no quadro museológico. Relevo a exposição que organizei intitulada Espaços de Festa: Permanência e Inovação, que teve em lugar em novembro de 1991, no próprio museu.

As dificuldades existentes não conseguiam ser ultrapassadas pelos responsáveis deste grupo de trabalho que, apesar da sua persistência, se via muitas vezes desencorajado por lutas inglórias.

Foi curta a minha permanência no Centro de Antropologia Cultural/Museu de Etnologia, de outubro de 1973 a maio de 1974. A inexistência de qualquer vínculo oficial que me ligasse ao Centro e a limitação das verbas disponíveis, que em muito dificultava a concretização de qualquer projeto, fizeram-me, com muita pena, interromper a minha presença num espaço ocupado por tão ilustres investigadores, com quem continuei a manter uma colaboração permanente. A equipa sénior analisou comigo, de forma séria e muito objetiva, a proposta feita pelo professor Fraústo da Silva, então encarregado de constituir uma equipa que desse corpo à Universidade Nova de Lisboa, empreendimento que 
tinha em mãos. Equacionar as duas possibilidades que se apresentavam - ficar ou sair - foi muito difícil e provocou-me uma angústia que confesso sem vergonha. Pode dizer-se que a transferência para uma outra instituição correspondeu ao desfazer-se de um sonho. E, com o otimismo que me caracteriza, encetei em maio de 1974 um outro caminho, que então abria horizontes atrativos e onde as ciências sociais ocupavam um lugar de destaque. Ou não estivéssemos no período pós-revolução...

MP Que memória guarda da vivência de trabalho com a equipa de Jorge Dias?

MBR-T Infelizmente o professor Jorge Dias partira deixando um irreparável vazio, e era recordado por todos os elementos da equipa quase diariamente. A sua falta, manifestada regularmente pela evocação do seu nome, das suas ideias e da orientação que poderia ter dado, se estivesse vivo, aos trabalhos que então decorriam, constituía uma realidade inalterada. Nesse espaço era totalmente impossível separar o profissional do privado - o prazer que trazia a convivência social, feita com delicadeza e respeito recíproco, marca a qualidade do ambiente que reinava. Relações de amizade e de parentesco articularam-se em torno de interesses comuns, possibilitando aos investigadores que constituíam esta equipa estabelecer a conjugação de competências que sempre confluiu para um mesmo propósito. Foi neste ambiente de trabalho onde o relacionamento era muito cordial que passei a integrar a equipa dos três colaboradores mais jovens. Ao iniciar funções no quadro profissional acima descrito, fui instalada numa sala ampla virada para o jardim, que partilhei com Margot Dias. Como mobiliário, duas secretárias colocadas em ângulo reto apoiavam o trabalho de cada uma de nós. A sala possuía duas estantes muito simples e um estreito divã com cobertura azul forte, que possibilitava àquela investigadora o repouso que, por questões de saúde, obrigatoriamente deveria cumprir em períodos alternados. Tal raramente acontecia.

O número dos que exerciam funções de investigação restringia-se aos nomes que passo a indicar e as salas por eles ocupadas alojavam em regra duas pessoas: numa, estavam instalados, certamente pela afinidade e proximidade da origem e formação, António Carreira e Rogado Quintino; numa outra, Ernesto Veiga de Oliveira e Benjamim Pereira; em conjunto trabalhavam Carlos Ramos de Oliveira e Carlos Laranja Medeiros; individualmente, exercia funções a responsável pela Biblioteca e Centro de Documentação, Helena Prista Monteiro; Ruy Cinatti (engenheiro agrónomo, com uma formação em antropologia pela Universidade de Oxford e grande poeta) auferia de uma posição de maior independência. Ao profissionalismo e arte do fotógrafo Carlos Ladeira devem-se muitas das belíssimas imagens, que não só animaram a obra escrita como as exposições da equipa. Não pode deixar de ser referido o Jaime, cujas funções de natureza prática, sendo indispensáveis, constituíram um contributo de grande 
valor. Sem o trabalho por ele desempenhado, que muito ajudou a manutenção e o funcionamento do museu, teriam surgido sérias dificuldades.

Subsequentemente à minha entrada, que já referi, o viver do dia a dia proporcionou-me numa primeira estadia um ambiente muito agradável. À excelência do quadro de trabalho em que reinava o bom entendimento e à troca de impressões abertas possibilitada pela expressão franca dos projetos que continuadamente surgiam, opunha-se a completa falta de condições materiais para trabalhar e a inexistência de recursos para o fazer.

De facto, as relações que tive com a equipa de Jorge Dias, com cada um deles e com todo o conjunto, no âmbito de uma continuada relação pessoal/profissional que sempre mantive ao longo de muitos anos, proporcionaram a aquisição de valiosas competências e inspiraram os caminhos que posteriormente vim a percorrer. Para além de tudo o que se encontrava relacionado com o trabalho em curso e com o gizar de projetos futuros, um sentimento recíproco de forte ligação emocional ligava os elementos que o constituíam. As conversas estabelecidas incidiam não só sobre o que respeitava ao quotidiano, mas ultrapassavam-no largamente.

Muitas refeições foram tomadas em conjunto, no próprio espaço de trabalho; outras foram partilhadas em locais considerados "únicos", por só a eles poder ter acesso quem os conhecia. Lembro, por exemplo, um pequeno café no interior do bairro de Alcântara, onde só se podia aceder por conhecimento previamente estabelecido entre a proprietária guineense e António Carreira. Aí nos deliciávamos em conjunto com a receita do caldo de peixe, mafefede, prato típico da Guiné-Bissau feito à base de tainhas secas, com arroz, malagueta e piripíri. Um olhar retrospetivo permite equacionar uma dúvida sobre a má qualidade do local onde nos instalávamos e era tomada a refeição (uma sala interior, sem janela), e o prazer que nos trazia projetá-la, o gosto do sabor exótico que recordo ainda hoje e o delicioso convívio que se estabelecia. Um outro dos restaurantes frequentados, quando a refeição era partilhada com algum colega externo à instituição, merecedor de uma especial atenção, situava-se na Rua dos Jerónimos, na lateral do Mosteiro; ainda frequentado com regularidade lembro um outro, localizado na esquina da Rua Correia Garção com a de São Bento.

MP Qual o efeito da preparação em antropologia na sua vida profissional?

MBR-T Toda a produção científica da equipa de Jorge Dias teve uma reconhecida influência sobre a forma como percorri toda a vida profissional. Assumo-o publicamente com honra e com orgulho e nunca é demais referir como a qualidade que caracterizou a investigação desenvolvida pelos elementos do grupo se repercutiu na orientação e no tratamento dos temas que estudei.

Sendo diversificada a área de estudo que constituiu objeto da equipa, que se deslocou por vários espaços do então império português, sempre considerando 
o Homem na sua unidade e valorizando as diferentes expressões culturais que reconhecia, foram desenvolvidos vários projetos que podem ser considerados indicadores da riqueza da sua qualidade editorial. Os temas ligados à cultura ocidental, nomeadamente a Portugal, sempre constituíram para mim um grande atrativo, o mesmo não tendo acontecido com os que se ligavam ao continente africano ou tiveram por objeto o Oriente.

Iniciada pelo professor Jorge Dias a investigação realizada no Norte de Portugal, em Vilarinho da Furna (1948) e, posteriormente, em Rio de Onor (1953), duas aldeias comunitárias que abriram portas aos "estudos de comunidade" na academia portuguesa, seguiram-se, com desenvolvimento paralelo, os itinerários percorridos e a recolha de informação por Veiga de Oliveira e Benjamim Pereira, que lhe deram uma continuidade notável. Assumiram desta forma uma postura que priorizava o registo da tradição portuguesa, muito em especial em relação à cultura material. Foram seguidores dos que em França também tinham sido guiados pelos princípios da "ethnologie d’urgence", encetada por investigadores ligados ao Musée de l'Homme, em Paris.

Ter procurado realizar trabalho de campo, estar inserida nos espaços que constituíam objeto da informação que procurava, ter interagido com os elementos das microssociedades a que cada um deles pertencia, conduziu-me a tomar uma abordagem metodológica que sempre priorizou o qualitativo. Embora os valores quantitativos tivessem apoiado as hipóteses levantadas e confirmado as interpretações feitas, considero que uma perspetiva socioantropológica guiou o encaminhamento de todos os meus trabalhos. A importância da imagem, sempre por mim associada a qualquer conhecimento que procurasse registar ou transmitir, decorre da influência sofrida através das obras produzidas em colaboração com o Instituto do Filme Científico de Göttingen e de toda a recolha e montagem fotográficas feitas por Benjamim Pereira e Carlos Ladeira. Uma outra iniciativa que considero interessante, por ter sido inovadora, foi o ensino da disciplina de Antropologia Visual, que integrava o segundo módulo do programa do mestrado de Relações Interculturais (1991) e que ainda hoje continua a ser lecionada pela Universidade Aberta.

Às séries que produzi no âmbito do Instituto Português de Ensino à Distância e da Universidade Aberta como material letivo destinado aos cursos ministrados à distância (Iniciação à Museologia, 1993, e Sociologia das Migrações, 1995) e para a televisão, que transmitiu os quatro programas que integravam O Sonho do Emigrante (1988), junta-se a série Festas (1984). ${ }^{3}$ Esta última série

3 As imagens para a realização dos vídeos sobre festas, título que a série assumiu, foram colhidas na Pateira de Fermentelos; em Lamego, na Festa de Nossa Senhora dos Remédios; em Fátima, em 13 de agosto; em Sul, quando da inauguração do monumento ao emigrante. Campo Maior, o último local estudado, mereceu particular atenção pela conhecida Festa das Flores. De ressaltar o acompanhamento no terreno feito por Benjamim Pereira e Ernesto Veiga de Oliveira. 
foi subsidiada pela então Secretaria de Estado da Emigração. O registo das celebrações religiosas e profanas em que os migrantes portugueses se envolviam durante os meses de verão constituiu motivo suficientemente forte para que a Secretaria de Estado tivesse concedido um subsídio em troca da sua integração no ciclo de cinema que, por seu intermédio, era projetado no estrangeiro.

A atração que sempre tive pela instituição fez-me tentar uma segunda hipótese de integrar a equipa. Mais uma vez o percurso não foi fácil e, tendo que prestar provas num concurso para investigador/coordenador, apresentei candidatura ao concurso que tinha sido aberto (1990).

Desta vez ficaria instalada no novo edifício, numa lindíssima sala com vista para o Tejo. As condições de trabalho então existentes, sempre difíceis, quase tinham desaparecido por completo. O Museu fora separado dos centros e passava a ter uma vida própria; o equipamento fora adstrito a cada uma das instituições com um critério de atribuição totalmente incompreensível. Para os investigadores, nem sequer havia possibilidade de solicitar fotocópias, ainda que sendo pagas.

Nestas condições, o convite e imposição para ocupar o lugar de diretora do Centro de Antropologia Cultural e Social revelava-se uma situação de grande complexidade e foram em vão todos os esforços feitos para ultrapassar as dificuldades que surgiam. José Carlos Gomes da Silva, antropólogo ilustre, pedira a sua demissão do lugar que me era agora oferecido. Nunca nos encontrámos neste espaço em situação de trabalho, embora as nossas relações tivessem sido as melhores. Só depois viria a compreender a razão que motivou a sua saída, após uma tão curta permanência na instituição que deixava por razões evocadas na conversa que coincidiu com a minha entrada.

A conjugação das três instituições acima referidas numa mesma área de trabalho e nela estando inserida uma mesma equipa permitiu produzir resultados que alimentavam projetos, dando corpo à articulação de esforços complementares.

O número de investigadores tinha-se progressivamente reduzido e, depois da morte de Jorge Dias (1973), de Ernesto Veiga de Oliveira (1990) e de Fernando Galhano (1995), a equipa desfez-se. Tudo se tinha alterado.

A ilusão que sustentara para a minha carreira profissional ao longo de muitos anos caminhava, sem qualquer alternativa, para o fim... Resta bem viva a recordação de um projeto aliciante que alimentara com muito empenho e o desencanto de não o ter conseguido construir. 